Impact of bio-palladium nanoparticles (bio-Pd NPs) on the activity and structure of a marine microbial community

Peer-reviewed author version

Nuzzo, Andrea; HOSSEINKHANI, Baharak; Boon, Nico; Zanaroli, Giulio \& Fava, Fabio (2017) Impact of bio-palladium nanoparticles (bio-Pd NPs) on the activity and structure of a marine microbial community. In: ENVIRONMENTAL POLLUTION, 220, p. 1068-1078.

DOI: 10.1016/j.envpol.2016.11.036

Handle: http://hdl.handle.net/1942/23255 
Manuscript Number:

Title: Impact of bio-palladium nanoparticles (bio-Pd NPs) on the activity and structure of a marine microbial community

Article Type: Research Paper

Keywords: Bio-Pd NPs; Nanoparticles; Ecotoxicity; Marine sediment; Bacterial community structure

Corresponding Author: Dr. Giulio Zanaroli, Ph.D.

Corresponding Author's Institution: University of Bologna

First Author: Andrea Nuzzo

Order of Authors: Andrea Nuzzo; Baharak Hosseinkhani; Nico Boon; Giulio Zanaroli, Ph.D.; Fabio Fava

Abstract: Biogenic palladium nanoparticles (bio-Pd NPs) represent a promising catalyst for organohalide remediation in water and sediments. However, the available information regarding their possible impact in case of release into the environment, particularly on the environmental microbiota, is limited. In this study the toxicity of bio-Pd NPs on the model marine bacterium $V$. fischeri was assessed. The impacts of different concentrations of bio-Pd NPs on the respiratory metabolisms (i.e. organohalide respiration, sulfate reduction and methanogenesis) and the structure of a PCB-dechlorinating microbial community enriched form a marine sediment were also investigated in microcosms mimicking the actual sampling site conditions. Bio-Pd NPs had no toxic effect on V. fischeri. In addition, they had no significant effects on PCB-dehalogenating activity, while showing a partial, dose-dependent inhibitory effect on sulfate reduction as well as on methanogenesis. No toxic effects by bioPd NPs could be also observed on the total bacterial community structure, as its biodiversity showed a NPs dose-dependent increase compared to the not exposed community. In addition, resilience of the microbial community to bio-Pd NPs exposure was observed, being the final community organization (Gini coefficient) of samples exposed to bio-Pd NPs similar to that of the not exposed one. Considering all the factors evaluated, bio-Pd NPs could be deemed as non-toxic to the marine microbiota in the conditions tested. This is the first study in which the impact of bio-Pd NPs is extensively evaluated over a microbial community in relevant environmental conditions, providing important information for the assessment of their environmental safety. 


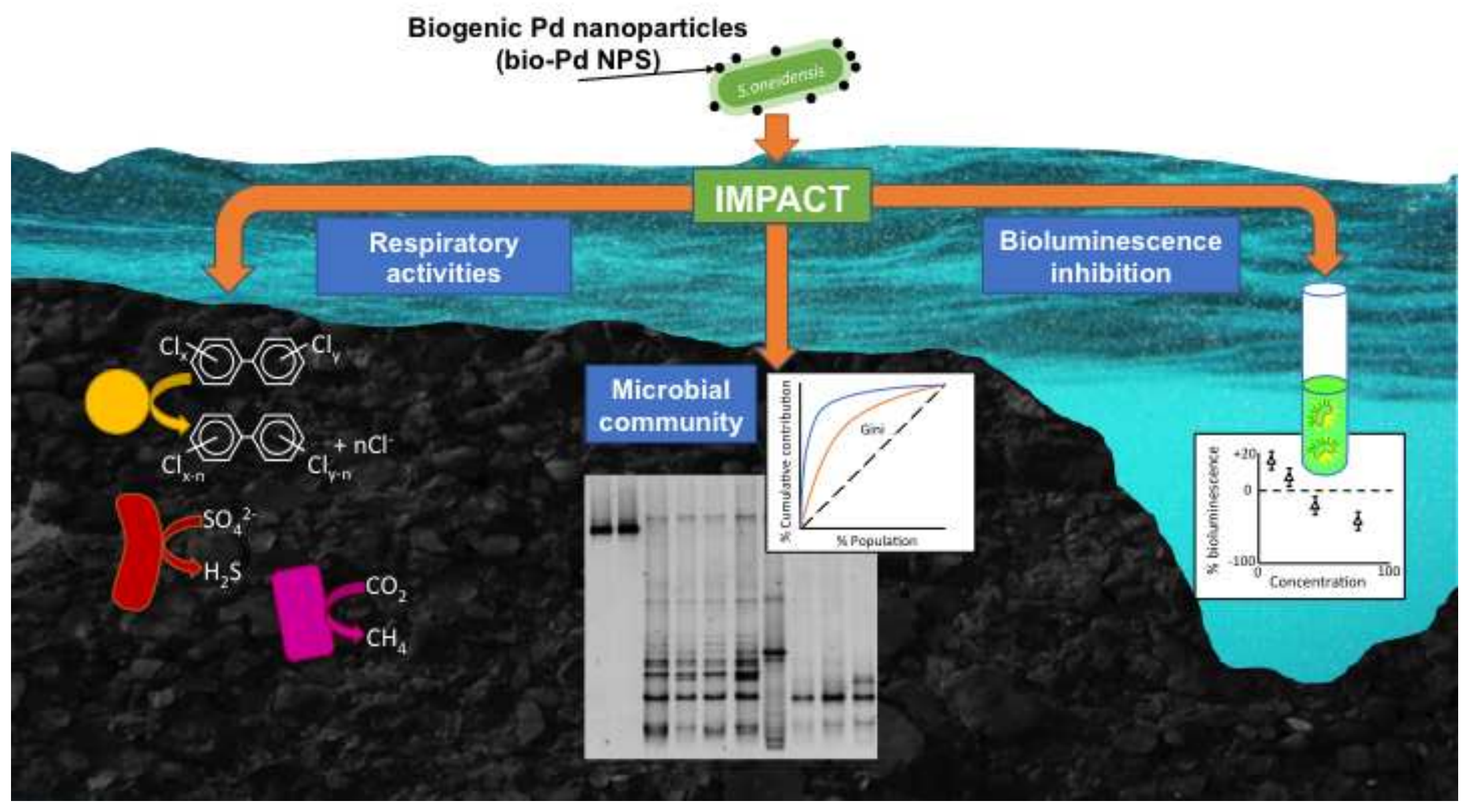


Highlights:

- Bio-Pd NPs are deemed not toxic in standard $V$. fischeri ecotoxicity test

- Impact of Bio-Pd NPs tested on microbial community in its native sediment and water

- Bio-Pd NPs impact is limited to few respiratory activities

- Microbial community is resilient to bio-Pd NPs 
1 Impact of bio-palladium nanoparticles (bio-Pd NPs) on the activity and structure of a marine

2

3

4

5

7

\title{
microbial community
}

\author{
Andrea Nuzzo $^{\mathrm{a}}$, Baharak Hosseinkhani ${ }^{\mathrm{bt}}$, Nico Boon ${ }^{\mathrm{b}}$, Giulio Zanaroli ${ }^{*}$, Fabio Fava ${ }^{\mathrm{a}}$
}

a) Department of Civil, Chemical, Environmental and Materials Engineering, University of Bologna, Via Terracini 28, 40131 Bologna, Italy

b) Center for Microbial Ecology and Technology (CMET), Ghent University, Coupure Links 653, B9000 Gent, Belgium

† present address: Hasselt University, Biomedical research institute, Martelarenlaan 42, 3500 Hasselt, Belgium

* Corresponding author. E-mail: giulio.zanaroli@unibo.it ; Telephone: +39-051-2090317; Fax: +39051-2090322 


\section{Abstract}

Biogenic palladium nanoparticles (bio-Pd NPs) represent a promising catalyst for organohalide remediation in water and sediments. However, the available information regarding their possible impact in case of release into the environment, particularly on the environmental microbiota, is limited. In this study the toxicity of bio-Pd NPs on the model marine bacterium $V$. fischeri was assessed. The impacts of different concentrations of bio-Pd NPs on the respiratory metabolisms (i.e. organohalide respiration, sulfate reduction and methanogenesis) and the structure of a PCB-dechlorinating microbial community enriched form a marine sediment were also investigated in microcosms mimicking the actual sampling site conditions. Bio-Pd NPs had no toxic effect on V. fischeri. In addition, they had no significant effects on PCB-dehalogenating activity, while showing a partial, dose-dependent inhibitory effect on sulfate reduction as well as on methanogenesis. No toxic effects by bio-Pd NPs could be also observed on the total bacterial community structure, as its biodiversity showed a NPs dose-dependent increase compared to the not exposed community. In addition, resilience of the microbial community to bio-Pd NPs exposure was observed, being the final community organization (Gini coefficient) of samples exposed to bio-Pd NPs similar to that of the not exposed one. Considering all the factors evaluated, bio-Pd NPs could be deemed as non-toxic to the marine microbiota in the conditions tested. This is the first study in which the impact of bio-Pd NPs is extensively evaluated over a microbial community in relevant environmental conditions, providing important information for the assessment of their environmental safety.

\section{Keywords}

Bio-Pd NPs, Nanoparticles, Ecotoxicity, Marine sediment, Bacterial community structure

52

53

54

\section{Capsule}

Bio-Pd NPs are non-toxic towards V.fischeri and have a limited impact on a marine microbial community in site-mimicking microcosms. 
Nanoremediation is the application of reactive nanoparticles (NPs) for the detoxification of environmental matrices from pollutants (Karn et al., 2009); a long list of different nanomaterials have been applied so far in nanoremediation of contaminated water and soils, such as nanoscale zero-valent iron (nZVI) (Theron et al., 2008; Zhang, 2003), Pd/Fe bimetallic NPs, carbon nanostructures and many more (Theron et al., 2008). These NPs show very high reactivity and different properties compared to their bulk counterparts, due to their size and innovative surface coatings, allowing efficient and controllable degradation activities, especially against recalcitrant pollutants (Macé et al., 2006; Serrano, 2010). NPs of zerovalent iron represent a typical example of this approach, especially for the decontamination of groundwater from organic solvents, pesticides, dyes and polychlorinated hydrocarbons as well as inorganic ions (Zhang, 2003); more recently, other metal NPs have emerged as novel catalyst in nanoremediation approaches, called zerovalent palladium nanoparticles (Pd-NPs). Pd nano-catalysts were efficiently used for reductive dechlorination of several contaminants (Ukisu and Miyadera, 2003). Pd-NPs catalyse the reductive dehalogenation of the contaminant through the development of radical cathodic hydrogen which chemically dehalogenates the molecule (Choi et al., 2009; De Windt et al., 2005); additionally, NPs of zerovalent Pd can be obtained through bioprecipitation in bacterial cultures and they are referred to as biopalladium nanoparticles (bio-Pd NPs) (Baxter-Plant et al., 2003; De Windt et al., 2005). Bio-Pd NPs have been effectively used for the degradation/transformation of contaminants such as heavy metals, halogenated organic solvents and pesticides in different environments, such as groundwater, wastewater, air, soil, sediments (De Corte et al., 2012) constituting promising catalysts (Hennebel et al., 2009) in an effective cradle to cradle approach which combine recovery of this precious metal from wastewater and a sustainable approach in pollutant nanoremediation (Hennebel et al., 2012). Among halogenated compounds, polychlorinated biphenyls (PCBs) are persistent organic pollutants with toxic effects on all trophic levels, including humans (Safe, 1993). Due to their high hydrophobicity, recalcitrance to biodegradation, biomagnification capabilities throughout the food chain and toxic effects on both the environment and the human health, PCBs are still included in the Priority Organic Pollutants list (Stockholm Convention, 2004). After more than 30 years from worldwide production banishment, PCB pollution is still present in marine environments, especially in sediments (Fernández and Grimalt, 2003). In these environmental compartments some microorganisms of the phylum Chloroflexi are able to use them as final electron acceptor. Through this activity, 
chlorine atoms are sequentially removed from the highly chlorinated PCB congeners leading to the accumulation of lower chlorinated ones which have usually lower toxicity and can be more easily degraded in aerobic conditions (Sowers and May, 2013; Zanaroli et al., 2015). This process known as microbial reductive dechlorination, has been mainly studied in freshwater sediment cultures (Bedard, 2008; Field and Sierra-Alvarez, 2008; Wiegel and Wu, 2000), whereas less is known regarding these activities in marine sediments (Fava et al., 2003a, 2003b; Zanaroli et al., 2015, 2006). In addition, microbial reductive dechlorination processes are extremely slow (Wiegel and $\mathrm{Wu}, 2000$ ) and enhancement strategies must be developed for bioremediation approaches to compete with the traditional remediation technologies, which are environmentally and economically unsustainable (Khan et al., 2004; Perelo, 2010).

Bio-Pd NPs have been recently suggested as a promising approach to enhance PCB degradation also in marine environments, where they can be synthesized by some indigenous marine microorganisms (Hosseinkhani et al., 2014b). Using these biologically precipitated NPs, a complete dechlorination of TCE was achieved in synthetic marine water and marine slurries of water and sediments (Hosseinkhani et al., 2014a, 2014b) as well as an extensive dechlorination of Aroclor 1254 PCBs to mainly monochlorobiphenyls (Hosseinkhani et al., 2015). However, concerns are rising around the environmental remediation approaches using these NPs (Grieger et al., 2010; Karn et al., 2009; Otto et al., 2008; Sánchez et al., 2011); metal NPs might have toxic effects on humans and on the environment, due to their small dimensions, which allow them to penetrate easier and faster into the cell space (Jiang et al., 2009; Schrand et al., 2010). Pd- NPs, in particular, have an inhibiting effect on E. coli and S. aureus (Adams et al., 2014), kiwifruit pollen development (Speranza et al., 2010) and peripheral blood mononuclear cells (Petrarca et al., 2014). It is therefore necessary to evaluate risk factors of Pd-NPs as well as other metallic NPs via standardized tests before their application (Nowack and Bucheli, 2007; Wiesner et al., 2006). Particularly, the information on their impact on the active microbial community (Farré et al., 2008; Sánchez et al., 2011), which is the most important player in 114 bioremediation processes, is missing.

115 Therefore, the aim of this work was to assess the ecological toxicity of bio-Pd NPs in marine 116 environment using Microtox ${ }^{\circledR}$ standardized acute toxicity test (Ma et al., 2014) and to evaluate their 117 impact on a PCB-dehalogenating marine microbial community in its contaminated sediments of origin. 118 In particular, the effects on the main respiratory metabolisms of the examined microbial community 119 (i.e., dechlorination, sulfate reduction and methanogenesis), as well as on the total bacterial community structure were assessed. 
122 Materials and Methods

123 Preparation of bio-Pd NPs

124 Preparation of bio-Pd NPs was performed through bioprecipitation with Shewanella oneidensis pure 125 cultures according to De Windt, et al. (2005).

126

127 Ecotoxicity tests on $V$. fischeri

128 Acute toxicity of bio-Pd NPs was measured by assessing luminescence inhibition of the marine Gram129 negative bacterium V. fischeri (strain NRRL B-11177) with a Microtox ${ }^{\circledR}$ M500 (Modern Water 130 Monitoring, Cambridge, UK) after 5, 15 and 30' exposure to serial 2-fold dilutions of a bio-Pd NPs 131 solution at $9.5 \mathrm{ppm}$ (equivalent to $50 \mathrm{mg} / \mathrm{kg}$ dry sediment condition). The luminescence signals were 132 normalized against an active control with no bio-Pd NPs using the MicroTox Omni Software, 133 according to the $81.9 \%$ Basic Test Protocol provided by the manufacturer. The concentration of the 134 sample (ppm) which produces a 50\% decrease in bioluminescence after exposure is designated as the 135 effective concentration $\mathrm{EC}_{50}$.

136

\section{Microcosm preparation and sampling}

138 The impact of bio-Pd NPs on a PCB-dechlorinating marine microbial community previously enriched from a sediment collected from the Venice lagoon (Italy) was tested by sub-culturing the community in anaerobic $70 \mathrm{ml}$ slurry microcosms prepared as follows. First, sediment from the Venice lagoon was autoclave-sterilized at $121^{\circ} \mathrm{C}$ for $1 \mathrm{~h}$ on 3 consecutive days with incubation at $28{ }^{\circ} \mathrm{C}$ between each autoclaving treatment. $1600 \mathrm{ml}$ of site water were purged in a 11 Erlenmeyer flask with filter-sterilized $\mathrm{N}_{2}: \mathrm{CO}_{2}$ (70:30) with a Hungate-similar apparatus for $2 \mathrm{~h}$ under vigorous magnetic stirring. Then,

144 degassed water was filter-sterilized and added to the autoclaved sediment to obtain a $20 \%$ (dry w/v) suspension and the resulting slurry was mixed and purged as described above for 2 additional hours. Seventy $\mathrm{ml}$ aliquots of sediment slurry were then withdrawn while mixing and purging, and transferred into $120 \mathrm{ml}$ serum bottles and sealed with Teflon-coated butyl stoppers under $\mathrm{N}_{2}: \mathrm{CO}_{2}$ flush. Three sets of microcosms were prepared: i) a set inoculated (5\% v/v) with the PCB dechlorinating culture and spiked with the PCB mixture Aroclor 1254 (from a $20 \mathrm{~g} / 1$ stock solution in acetone) at a final concentration of $1 \mathrm{~g} / \mathrm{kgdw}$; ii) a set inoculated $(5 \% \mathrm{v} / \mathrm{v})$ with the same culture but not spiked with 
152 inoculated (i.e., sterile) and spiked with Aroclor 1254 at a final concentration of $1 \mathrm{~g} / \mathrm{kgdw}$. The two

153 sets spiked with PCBs comprised the following conditions: i) not amended microcosms (biologically 154 active and sterile controls), ii) microcosms amended with $\mathrm{H}_{2}: \mathrm{CO}_{2}$ (70:30) atmosphere, as control to 155 investigate the effect of hydrogen, required for bio-Pd catalytic activity, on respiratory activities and 156 the community structure (inoculated, i.e., biologically active set) and as additional negative control for 157 PCB chemical dechlorination (not inoculated, i.e., sterile set), (iii) microcosms amended with $\mathrm{H}_{2}: \mathrm{CO}_{2}$ 158 (70:30) atmosphere and bio-Pd NPs at $5 \mathrm{mg} / \mathrm{kgdw}$ and iv) amended with $\mathrm{H}_{2}: \mathrm{CO}_{2}$ (70:30) atmosphere 159 and bio-Pd NPs at $50 \mathrm{mg} / \mathrm{kgdw}$, to study the effect of different bio-Pd NPs concentrations on the 160 community activity and structure (biologically active set) and the PCB dechlorination activity of bio161 Pd NPs (sterile set). The inoculated set that was not spiked with PCBs included all conditions above 162 except for the not amended microcosms, and was set up to confirm the effect of bio-Pd NPs on the 163 activity and structure of the microbial community in the absence of organic contaminants. Triplicate microcosms were set up for each condition. All microcosms were incubated statically in the dark at $28^{\circ} \mathrm{C}$ and periodically sampled according to the procedure described in Zanaroli et al. (2012a) to analyse i) the volume and composition of the biogas produced in the microcosm headspace, ii) the type and concentrations of PCBs in the sediment, iii) the concentration of sulfates in the water phase, iv) the structure of the microbial community.

\section{$P C B$ extraction and analytical procedures}

171 PCB extraction was performed in duplicate from each replicate culture. PCBs were batch extracted 172 from $0.3 \mathrm{~mL}$ aliquots of sediment slurry with 3 volumes $(0.9 \mathrm{ml})$ of hexane:acetone $(9: 1), 0.150 \mathrm{ml}$ of 173 elemental mercury and octachloronaphtalene $(\mathrm{OCN})$ at final concentration of $0.4 \mathrm{ppm}$ were added according to Fava et al. (2003). The qualitative and quantitative analyses of the extracted PCBs were performed with a GC-ECD under the analytical conditions described elsewhere (Fava et al., 2003a). Qualitative analysis of the freshly spiked PCBs and their possible dechlorination products was performed by comparing the retention time (relative to $\mathrm{OCN}$ ) of the peaks obtained from the analyses of the sediment organic extracts with those of PCBs occurring in Aroclor 1242 and Aroclor 1254 PCB standard mixtures analysed under identical conditions. Quantitative analyses of each PCB congener were performed by using the GC-ECD response factor of each target PCB obtained through linear fivepoints calibration curves of Aroclors 1254 and 1242 (in the range 1 to $50 \mathrm{ppm}$ each mixture) as described in Fava et al. (2003a). Response factors were verified monthly. PCB concentrations 
$184 \mathrm{kgdw}$ per week) were calculated assuming co-eluting congeners to be present in equal proportions as 185 described in previous works (Zanaroli et al., 2010).

186 Biogas production was measured at each sampling with an airtight glass syringe, while its composition 187 was determined via $\mu \mathrm{GC}-\mathrm{TCD}$ as described previously (Scoma et al., 2011). Sulfate concentration in

188 the water phase was determined with IC-CD as described in (Fava et al., 2003a); linear 5-point calibration curves (1.0-25.0 ppm range) for $\mathrm{SO}_{4}{ }^{2-}, \mathrm{Cl}^{-}, \mathrm{NO}_{3}{ }^{-}$and $\mathrm{NO}_{2}{ }^{-}$were obtained by using mixtures of these compounds.

\section{Community analysis by PCR-DGGE of the 16S rRNA gene}

193 Slurry samples $(2 \mathrm{ml})$ were centrifuged at 10,000 $\mathrm{g}$ for 10 minutes and the water phase was discarded; 194 metagenomic DNA was extracted from the wet sediment (approximately $250 \mathrm{mg}$ ) recovered DNA was 195 extracted with the PowerSoil DNA extraction kit (MoBio Laboratories, Carlsbad, CA, USA) according 196 to the protocol provided by the manufacturer. Sediment samples suspended in the bead solution 197 supplied with the kit were treated with $4.5 \mu 1$ of a $100 \mathrm{mg} \mathrm{ml}^{-1}$ Proteinase K solution from Streptomices 198 griseus (Sigma-Aldrich, Milano, Italy) and $8.2 \mu \mathrm{l}$ of a $100 \mathrm{mg} \mathrm{ml}^{-1}$ of chicken egg Lysozyme (Sigma199 Aldrich, Milano, Italy) solution at $37^{\circ} \mathrm{C}$ under shaking at $150 \mathrm{rpm}$ for $30 \mathrm{~min}$, prior to cell lysis step 200 described in the provided protocol.

201 For DGGE analysis, 16S rRNA genes of the bacterial community were PCR amplified from the 202 metagenomic DNA with the GC-clamped forward primer GC-357f (5'CGCCCGCCGCGCCCCGCGCCCGGCCCGCCGCCCCCGCCCCCCTACGGGAGGCAGCAG-3’) and the reverse primer 907r (5'-CCGTCAATTCCTTTGAGTTT-3') (Sass et al., 2001) with PCR conditions described elsewhere (Zanaroli et al., 2012b). DGGE of bacterial amplicons (approximately 400 ng DNA per lane) were performed with a D-Code apparatus with a denaturing gradient from 40\% to $60 \%$ denaturant as described in Zanaroli et al. (2010). Gels were stained with SYBR Green I (Sigma-Aldrich, Milano, Italy) and their image captured in UV transilluminator with a digital camera supported by a Gel Doc apparatus (Bio-Rad, Milan, Italy). Community richness $(\mathrm{Rr})$ and community organization $(\mathrm{Co})$ indexes were calculated from DGGE image analysis as described in literature (Marzorati et al., 2008; Read et al., 2011; Wittebolle et al., 2009). In particular, the range-weighted richness was calculated from the total number of bands in the pattern and the denaturing gradient comprised between the first and the last band of the pattern, whereas the community organization was derived from Pareto-Lorenz (PL) evenness curves and the respective Gini coefficient times 100. 


\section{Results}

218 The impact of bio-Pd NPs was assessed firstly on a model marine bacterium, $V$.fischeri, by assessing eventual inhibition of its bioluminescence. Then, tests focused on the eventual impact of bio-Pd NPs on 220 the main respiratory metabolisms and the structure of a PCB dechlorinating marine microbial community. For this purpose, anaerobic sediment sub-cultures were set-up, in the presence and in the absence of spiked PCBs either: i) in absence of any amendments (unamended controls); ii) in presence of $70 \%$ hydrogen atmosphere, which is necessary for the catalytic activity of bio-Pd NPs; iii) in presence of $70 \%$ hydrogen atmosphere and two different concentrations of bio-Pd NPs.

\section{Acute toxicity standard tests with $V$. fischeri}

227 To assess the acute toxicity of bio-Pd NPs on the evolution of a marine microbial community, a standard test was performed by assessing of the decrease in luminance of $V$. fischeri in presence of different concentrations of nanoparticles. A slight inhibition of luminescence (12\%) was detected only after 5 minutes of incubation in the presence of the highest bio-Pd NPs concentration (Fig 1). In all other cases (both in terms of bio-Pd concentration and exposure time) stimulating effects were detected, as luminescence was higher than non-amended control (percentages of inhibition below $0 \%$ ). Therefore, no $\mathrm{EC}_{50}$ could be determined. Such a biostimulation effect might be due to the presence of some cell debris associated to the bio-Pd NPs. Therefore, bio-Pd NPs do not result to be toxic at the concentrations used in this experiment, that were previously shown to be effective in the dehalogenation of different organohalides in marine sediments (Hosseinkhani et al., 2015).

\section{Respiratory metabolisms}

The unamended control (hydrogen free and bio-Pd NPs free) showed the highest dechlorination activity among the whole PCB-spiked, biologically active microcosms: the average number of chlorine atoms per biphenyl molecule decreased from 5.1 to 4.3 in 18 weeks of incubation, leading to the depletion of $54 \pm 3 \%$ of penta- to octachlorinated congeners at the maximum rate of $243 \pm 16 \mu \mathrm{mol} \mathrm{Cl}$ removed week ${ }^{-1} \mathrm{kgdw}^{-1}$ (Fig 2). The presence of hydrogen in the headspace, either alone or in combination with bio-Pd NPs, decreased remarkably the dechlorination rates, all of which were less than half of unamended microcosms $\left(107 \pm 37,118 \pm 75\right.$ and $97 \pm 27 \mu$ moles of chlorine removed $\mathrm{kgdw}^{-1}$ 
247 NPs at $50 \mathrm{mg} / \mathrm{kgdw}$, respectively). The final average number of chlorine substitution after 18 weeks of 248 incubation resulted to be 4.7, 4.7 and 4.9, corresponding to depletion percentages of highly chlorinated 249 congeners as low as $25 \%, 24 \%$ and $21 \%$, for the hydrogen-amended microcosms with no bio-Pd NPs, 250 bio-Pd-NPs at $5 \mathrm{mg} / \mathrm{kgdw}$ and bio-Pd NPs at $50 \mathrm{mg} / \mathrm{kgdw}$, respectively (Fig 2). The dechlorination 251 specificity led to a predominant accumulation of 24-25-CB and 24-34/236-25-CB (14 mol \%) (Fig 3a). In addition, the high residual concentration of the main penta-chlorinated biphenyls of spiked Aroclor 1254 mixture indicates that the dechlorination process was still incomplete when the incubation stopped. Coherently with the lower activities in all hydrogen-amended microcosms, and regardless of bio-Pd NPs, lower percentages of tetra- and tri-chlorinated congeners were detected at the end of incubation with a specificity apparently not influenced by bio-Pd NPs (Fig. 3). From these observations, bio-Pd NPs do not seem to impact the microbial dechlorination activities. No dechlorination was detected in any of the sterile microcosms, regardless of hydrogen atmosphere and bio-Pd NPs amendments (Fig 2).

Regarding other respiring metabolisms, sulfate-reduction activities were marked in all biologically active microcosms: the initially occurring sulfates $(2.5 \mathrm{~g} / 1$ average $)$ were completely consumed in the not-amended active controls after 6 weeks of incubation. A similar sulfate consumption was detected in microcosms amended with hydrogen only, while sulfate was completely consumed only after 9 weeks of incubation in microcosms supplemented with hydrogen and bio-Pd NPs at $5 \mathrm{mg} / \mathrm{kgdw}$, and by the end of incubation in microcosms supplemented with hydrogen and $50 \mathrm{mg} / \mathrm{kgdw}$ of bio-Pd NPs (Fig 4a). Thus, a dose-depended inhibition of bio-Pd on sulfate reduction was observed. Similar dosedependent effect of bio-Pd on sulfate reduction was also detected in the PCB-free sediment microcosms (Fig 4a).

No sulfate reduction, nor methane accumulation, were observed in the sterile microcosms throughout incubation (data not shown). In PCB-dechlorinating microcosms, hydrogen atmosphere stimulated methanogenesis compared to the not amended control, leading to a production of $27 \mathrm{ml}$ of methane in the bio-Pd NPs-free microcosms versus $6 \mathrm{ml}$ in the unamended control after 18 weeks on incubation (Fig 4b). In addition to the positive effect of hydrogen, however, a negative effect of bio-Pd NPs on methanogenesis was detected, since $17 \pm 1$ and $13 \pm 1 \mathrm{ml}$ of methane were produced respectively in the microcosms amended with $5 \mathrm{mg} / \mathrm{kgdw}$ and $50 \mathrm{mg} / \mathrm{kgdw}$ of bio-Pd NPs, corresponding to $62 \%$ and $48 \%$, respectively, of the methane produced in the bio-Pd NPs-free control (Fig 4b). Similar dosedependent inhibition by bio-Pd NPs on methanogenesis was observed in the microcosms without PCBs, as the methane production decreased of $44 \%$ and $59 \%$ compared to hydrogen-amended bio-Pd 
NPs-free microcosms, in the presence of $5 \mathrm{mg} / \mathrm{kgdw}$ and $50 \mathrm{mg} / \mathrm{kgdw}$ bio-Pd NPs, respectively (Fig 280 $4 b)$.

\section{Influence of bio-Pd NPs on the microbial community composition}

To further verify the impact of bio-Pd NPs on the total microbial community, PCR-DGGE approach was used to determine variations in terms of Community organization (Co) and Richness (Rr) throughout incubation. PCR-DGGE analyses were carried out on the bacterial communities of biologically active microcosms at the beginning, at the half and at the end of incubation $(0,9$ and 18 weeks, respectively) (Figs 5 and 6).

A marked increase of community richness was detected in all hydrogen-amended dechlorinating microcosms, and especially in presence of bio-Pd NPs, which exhibited a dose-dependent increase effect. The final richness (Rr) values were 25, 30, and 29 for microcosms with hydrogen only, hydrogen and bio-Pd NPs at $5 \mathrm{mg} / \mathrm{kgdw}$ and hydrogen and bio-Pd NPs at $50 \mathrm{mg} / \mathrm{kgdw}$, respectively, while only 21 in unamended active controls (Fig 5). The community organization gradually decreased over time in the unamended controls, as the Co decreased from 40 to 32; on the contrary, all dechlorinating microcosms amended with hydrogen showed a transient decrease in evenness, followed by a successive re-organization, to reach final Co similar to values measured in the unamended dechlorinating control (Fig 5). Thus, bio-Pd NPs did not seem to exhibit any effect on the community organization of the microbial dechlorinating community, while apparently stimulating a richer microbiota.

The same analysis was also performed on microcosms without PCBs (Fig 6) revealing again a dosedependent increase effect by bio-Pd NPs on the richness of the bacterial community at the end of the incubation. In the absence of PCBs a decrease in community organization was observed over time. This suggests that the community re-organizes, possibly because of the loss of some selective pressure exerted by PCBs and thus of the competitive advantage of the organohalides respiring members, which possibly favoured other species as the dechlorinating species decay (Fig 6). However, no differences were observed in the community organization of bio-Pd amended and bio-Pd free microcosms, indicating the bio-Pd NPs do not affect significantly the community structure. 
310 The use of bioPd-NPs as remediation catalyst is currently gaining a momentum, providing an effective 311 strategy for the treatment of recalcitrant compounds such as azo dyes (Quan et al., 2015) or 312 organohalides (Hosseinkhani et al., 2014b; Mertens et al., 2007) in several contaminated matrices, such 313 as wastewater (Hennebel et al., 2012), groundwater (De Corte et al., 2012) and sediments 314 (Hosseinkhani et al., 2015). NPs in general may pose risk for aquatic environments (Moore, 2006) and 315 their delivery, either by in situ application or by accidental release, might result in unwanted effects which would eventually invalidate their benefits (Grieger et al., 2010; Karn et al., 2009; Schrand et al., 2010). The evaluation of the risk/benefit ratio is not trivial, due to the lack of standard experimental conditions and analytical protocols for nanoparticles in general (Crane et al., 2008; Grieger et al., 2010) which persists in spite of a huge research need, still unaddressed (US-EPA 2014, 2007). In addition, the literature regarding Pd-NPs toxic effect is quite scarce. It is known that they can exert antimicrobial effects (Adams et al., 2014) and that they might be toxic for some superior organisms (Lüderwald et al., 2016; Petrarca et al., 2014) but not for others (Kovrižnych et al., 2013; Shah and Belozerova, 2009). In this study, a standard V. fischeri-based ecotoxicity assay has been implemented, being currently referred as a standard test also for NPs toxicity (Sánchez et al., 2011). The test is more sensitive than other standard tests reported, such as D. magna toxicity (van Beelen, 2003), highly specific and recommended to investigate the toxicity of various metals. To the best of our knowledge, this is the first study in which such assay was used on Pd-NPs and the obtained results are dismissing hypotheses of toxic effect of this these NPs on marine bacteria.

Some limitations characterize standard ecotoxicity assays since they usually miss the interplay between different factors, affecting both the environmental fate of the delivered/dispersed nanoparticles and their interaction with the pollutant and the organisms (Nowack and Bucheli, 2007). To the best of our knowledge, no information on the toxicity of Pd-NPs over environmental microbial communities is available. Moreover, the effect of the natural organic matter, which occurs in complex environments such as aquatic sediments, should not be underestimated: it is well known that organic matter not only can change the catalytic properties of metal NPs, but can also affect exposure and toxicity to (micro)organisms (Wang et al., 2016). In addition, the bio-Pd NPs used for this study are embedded in the cell wall of killed $S$. oneidensis and this might influence their toxicity to bacteria, by limiting their entry into the cells or altering their interaction with the cell surface and the sediment organic matter; on the other hand, the cell lysis might generate free bio-Pd NPs over time, thus changing their potential impact. Therefore, prior actual delivery or accidental leaks into the environment, and regardless of their catalytic efficiency, bio-Pd NPs environmental impacts need to be assessed, i.e. on microbial activity 
342 and on microbial community structure. For all of these reasons, thorough tests were required in 343 matrices close to the environmental conditions and for longer incubation time than current standard 344 tests. Microcosms studies are a good compromise between the complexity of environmental matrices 345 and the need to get preliminary data on the impact of NPs over microbial communities (Echavarri346 Bravo et al., 2015), which then need be thoroughly investigated further in mesocosms (Holden et al., 347 2016). Therefore, tests were performed in microcosms of actual marine sediments and water, 348 inoculated with a known dehalogenating microbial community in biogeochemical conditions close to 349 those occurring in the real site: this allowed to evaluate both the catalytic activity and the impact of 350 bio-Pd NPs on the microbial community under environmental conditions and in a time frame suitable 351 for slow-growing anaerobic microorganisms. A culture enriched in organohalide respiring members 352 was selected because bio-Pd NPs could be used to complement biological reductive dechlorination 353 activities with catalytic dehalogenation in nanoremediation approaches.

354 In this study, a lack of catalytic activity by bioPd-NPs over PCBs was evidenced in the sterile sediment 355 microcosms. A similar lack of activity was already shown to occur for bioPd-NPs in another anoxic 356 sediment of the Venice Lagoon area, where it was due to some inhibiting effects of the environmental 357 matrix, i.e., sulfide-poisoning phenomena (Hosseinkhani et al., 2015). This further supports the 358 assumption that bio-Pd NPs are effective catalysts in low-sulfidogenic sediments, i.e., in presence of 359 low sulfate concentration or under more aerobic conditions (Hosseinkhani et al., 2015). The complex 360 matrix of sediments might as well have played an inhibiting role, since the environmental distribution, 361 fate and activity of many NPs could be influenced by phenomena of sequestration, adsorption and 362 chemical inactivation by humic acids (Shah and Belozerova, 2009; Wang et al., 2016). Further studies 363 could be performed on different sediments not affecting the catalytic activity of bioPd-NPs to exclude 364 their toxic effect on microbiota in effectively catalytic conditions; however, inactivation of bio-Pd NPs 365 is a possible occurrence in the actual sediment used in this study, making relevant the evaluation of 366 bio-Pd NPs impact on microbial communities independently from their activity.

367 A negligible effect of bio-Pd NPs was observed on organohalide respiration. It has been shown that 368 other zero-valent metal NPs, known to be effective enhancers of PCB reductive dechlorination 369 activities in marine sediments, such as zero-valent iron NPs (nZVI), (Zanaroli et al., 2012b) do exhibit 370 also a series of ecotoxic effects in the environment, recently reviewed extensively by Lefevre, et al. 371 (2015), which include severe impacts on organohalides respiring communities in groundwater (Barnes 372 et al., 2010) and soil (Tilston et al., 2013), either through shifts in the microbial composition (Tilston et 373 al., 2013) or direct inhibition (Z. M. Xiu et al., 2010). A dose-dependent inhibitory effect exerted by 
bioPd-NPs was evident on sulfate reduction and methanogenic activities. Literature data on the effect exerted on these respiratory metabolisms in anaerobic microbial communities by Pd-NPs or similar nanoparticles, such as nZVI, are limited and often contradictory: either inhibition of sulfate reduction activities (Barnes et al., 2010) or increase in sulfate reducing bacteria population (Kirschling et al., 2010), either increase in methane production (Hu et al., 2015) or its inhibition (Huang et al., 2016) were reported. Studies investigating the mechanisms of interaction between bio-Pd NPs and cells of different microbial species might be useful to understand why bio-Pd NPs exert an inhibitory effect on some respiratory metabolisms rather than others.

Microbial community analysis is a fundamental tool to investigate toxicity hypotheses on environmental microbial communities (Sánchez et al., 2011). Particularly, diversity highly influences microbial community efficiency (Tilman et al., 2014), but also evenness plays an important role under selective stress (Wittebolle et al., 2009). It would be expected that, in presence of a toxic compound, both indexes would significantly decrease in a marine community (Johnston and Roberts, 2009), due to a selective growth of the resistant community members. BioPd-NPs, instead, only slightly altered the structure of the microbial community. In addition, they had a clear positive effect on community richness, while causing only a temporary shift in its community organization, which was reversed at the end of incubation. These observations clearly indicate that bioPd-NPs have no significant effect of on the overall microbial community. In other studies, more remarkable changes in the microbial community composition with nZVI NPs were reported, which were interpreted as a toxic effect (Kirschling et al., 2010; Tilston et al., 2013; Z. ming Xiu et al., 2010); however, in these cases no analysis of the community richness and community organization was performed, not allowing a clear comparison of the overall effects of bioPd-NPs and nZVI-NPs on microbial communities. Also, the different catalytic mechanisms of these two NPs (nZVI are reagents, while Pd-NPs are catalysts) may explain the differences in the toxic behaviours, as the peculiar microbial community structure and the interplay among environmental factors and NPs can do (Lefevre et al., 2015). Finally, microbial communities in marine sediments often demonstrate the capacity to resist to perturbations; even when ecological shifts are observed, particular metabolic functions of the community might be uncoupled, making the community eventually resilient to external forces (Bowen et al., 2011). The marine sediment community used in this study showed resiliency to bio-Pd NPs. Although this property might mask possible toxic effects on some specific members of the community, combined with the lack of toxicity to $V$. fisheri and the limited influence on few respiration activities observed, this information further supports the lack of significant impacts of bio-Pd NPs on marine bacteria. Overall, these data 
406 also point out the importance of combining multiple tests addressing different types of effects (standard 407 ecotoxicity assays, monitoring of metabolic activities and community structure) to evaluate the impact 408 of NPs on the environmental microbiota.

\section{Conclusions}

411 Different approaches have been used to evaluate the effect of bio-Pd NPs on marine microbes and 412 communities, taking into consideration their main metabolic activities, their biodiversity and 413 community structure. Bio-Pd NPs do not exert toxicity towards the bioluminescent marine bacterium $414 V$. fisheri. They may have limited inhibitory effects selectively towards specific respiratory 415 metabolisms, such as sulfate reduction and methanogenesis, but not organohalide respiration. On the 416 other hand, an increase of the community biodiversity along with no permanent effects on its 417 community organization have been observed, indicating the lack of a significant impact on the 418 microbial community. Overall, these data combined dismiss hypotheses of ecological impact of bio-Pd 419 NPs on marine microbiota. The use of a combination of different approaches tailoring as many factors 420 as possible should be implemented when investigating the possible impact of NPs in the environment.

\section{Acknowledgements}

This study was supported by the European Commission [grant number 266473] (ULIXES Project).

\section{References}

Adams, C.P., Walker, K. a., Obare, S.O., Docherty, K.M., 2014. Size-Dependent Antimicrobial Effects 427 of Novel Palladium Nanoparticles. PLoS One 9, e85981. doi:10.1371/journal.pone.0085981

Barnes, R.J., Riba, O., Gardner, M.N., Singer, A.C., Jackman, S.A., Thompson, I.P., 2010. Inhibition of biological TCE and sulphate reduction in the presence of iron nanoparticles. Chemosphere 80, 554-562. doi:10.1016/j.chemosphere.2010.04.033

Baxter-Plant, V.S., Mikheenko, I.P., Macaskie, L.E., 2003. Sulphate-reducing bacteria, palladium and the reductive dehalogenation of chlorinated aromatic compounds. Biodegradation 14, 83-90. doi:10.1023/A:1024084611555

434 Bedard, D.L., 2008. A case study for microbial biodegradation: anaerobic bacterial reductive 
dechlorination of polychlorinated biphenyls-from sediment to defined medium. Annu. Rev. Microbiol. 62, 253-70. doi:10.1146/annurev.micro.62.081307.162733

Bowen, J.L., Ward, B.B., Morrison, H.G., Hobbie, J.E., Valiela, I., Deegan, L.A., Sogin, M.L., 2011. Microbial community composition in sediments resists perturbation by nutrient enrichment. ISME J. 5, 1540-1548. doi:10.1038/ismej.2011.22

Choi, H., Al-Abed, S.R., Agarwal, S., 2009. Catalytic Role of Palladium and Relative Reactivity of Substituted Chlorines during Adsorption and Treatment of PCBs on Reactive Activated Carbon. Environ. Sci. Technol. 43, 7510-7515. doi:10.1021/es901298b

Crane, M., Handy, R.D., Garrod, J., Owen, R., 2008. Ecotoxicity test methods and environmental hazard assessment for engineered nanoparticles. Ecotoxicology 17, 421-437. doi:10.1007/s10646$008-0215-\mathrm{z}$

De Corte, S., Hennebel, T., De Gusseme, B., Verstraete, W., Boon, N., 2012. Bio-palladium: From metal recovery to catalytic applications. Microb. Biotechnol. 5, 5-17. doi:10.1111/j.17517915.2011.00265.x

De Windt, W., Aelterman, P., Verstraete, W., 2005. Bioreductive deposition of palladium (0) nanoparticles on Shewanella oneidensis with catalytic activity towards reductive dechlorination of polychlorinated biphenyls. Environ. Microbiol. 7, 314-325. doi:10.1111/j.14622920.2005.00696.x

Echavarri-Bravo, V., Paterson, L., Aspray, T.J., Porter, J.S., Winson, M.K., Thornton, B., Hartl, M.G.J., 2015. Shifts in the metabolic function of a benthic estuarine microbial community following a single pulse exposure to silver nanoparticles. Environ. Pollut. 201, 91-99. doi:10.1016/j.envpol.2015.02.033

Farré, M. La, Pérez, S., Kantiani, L., Barceló, D., 2008. Fate and toxicity of emerging pollutants, their metabolites and transformation products in the aquatic environment. TrAC - Trends Anal. Chem. 27, 991-1007. doi:10.1016/j.trac.2008.09.010

Fava, F., Gentilucci, S., Zanaroli, G., 2003a. Anaerobic biodegradation of weathered polychlorinated biphenyls (PCBs) in contaminated sediments of Porto Marghera (Venice Lagoon, Italy). Chemosphere 53, 101-9. doi:10.1016/S0045-6535(03)00438-7

Fava, F., Zanaroli, G., Young, L.Y., 2003b. Microbial reductive dechlorination of pre-existing PCBs and spiked 2,3,4,5,6-pentachlorobiphenyl in anaerobic slurries of a contaminated sediment of 
Fernández, P., Grimalt, J.O., 2003. On the Global Distribution of Persistent Organic Pollutants. Chim. Int. J. Chem. 57, 514-521. doi:10.2533/000942903777679000

468

469

470

471

472

473

474

475

476

477

478

479

480

481

482

483

484

485

486

487

488

489

490

491

492

493

494

Field, J. a, Sierra-Alvarez, R., 2008. Microbial transformation and degradation of polychlorinated biphenyls. Environ. Pollut. 155, 1-12. doi:10.1016/j.envpol.2007.10.016

Grieger, K.D., Fjordbøge, A., Hartmann, N.B., Eriksson, E., Bjerg, P.L., Baun, A., 2010. Environmental benefits and risks of zero-valent iron nanoparticles (nZVI) for in situ remediation: risk mitigation or trade-off? J. Contam. Hydrol. 118, 165-83. doi:10.1016/j.jconhyd.2010.07.011

Hennebel, T., De Corte, S., Verstraete, W., Boon, N., 2012. Microbial production and environmental applications of $\mathrm{Pd}$ nanoparticles for treatment of halogenated compounds. Curr. Opin. Biotechnol. 23, 555-561. doi:10.1016/j.copbio.2012.01.007

Hennebel, T., Simoen, H., Windt, W. De, 2009. Biocatalytic dechlorination of trichloroethylene with bio-palladium in a pilot-scale membrane reactor. Biotechnol. Bioeng. 102, 995-1002. doi:10.1002/bit.22138

Holden, P.A., Gardea-Torresdey, J.L., Klaessig, F., Turco, R.F., Mortimer, M., Hund-Rinke, K., Cohen Hubal, E.A., Avery, D., Barceló, D., Behra, R., Cohen, Y., Deydier-Stephan, L., Ferguson, P.L., Fernandes, T.F., Herr Harthorn, B., Henderson, W.M., Hoke, R.A., Hristozov, D., Johnston, J.M., Kane, A.B., Kapustka, L., Keller, A.A., Lenihan, H.S., Lovell, W., Murphy, C.J., Nisbet, R.M., Petersen, E.J., Salinas, E.R., Scheringer, M., Sharma, M., Speed, D.E., Sultan, Y., Westerhoff, P., White, J.C., Wiesner, M.R., Wong, E.M., Xing, B., Steele Horan, M., Godwin, H.A., Nel, A.E., 2016. Considerations of Environmentally Relevant Test Conditions for Improved Evaluation of Ecological Hazards of Engineered Nanomaterials. Environ. Sci. Technol. 50, 6124-6145. doi:10.1021/acs.est.6b00608

Hosseinkhani, B., Hennebel, T., Boon, N., 2014a. Potential of biogenic hydrogen production for hydrogen driven remediation strategies in marine environments. N. Biotechnol. 31, 445-50. doi:10.1016/j.nbt.2014.04.005

Hosseinkhani, B., Hennebel, T., Van Nevel, S., Verschuere, S., Yakimov, M.M., Cappello, S., Blaghen, M., Boon, N., 2014b. Biogenic nanopalladium based remediation of chlorinated hydrocarbons in marine environments. Environ. Sci. Technol. 48, 550-557. doi:10.1021/es403047u

Hosseinkhani, B., Nuzzo, A., Zanaroli, G., Fava, F., Boon, N., 2015. Assessment of catalytic 
dechlorination activity of suspended and immobilized bio-Pd NPs in different marine conditions. Appl. Catal. B Environ. 168-169, 62-67. doi:10.1016/j.apcatb.2014.12.014

$\mathrm{Hu}, \mathrm{Y}$. , Hao, X., Zhao, D., Fu, K., 2015. Enhancing the $\mathrm{CH} 4$ yield of anaerobic digestion via endogenous $\mathrm{CO} 2$ fixation by exogenous H2. Chemosphere 140, 34-9. doi:10.1016/j.chemosphere.2014.10.022

Huang, Y.-X., Guo, J., Zhang, C., Hu, Z., 2016. Hydrogen production from the dissolution of nano zero valent iron and its effect on anaerobic digestion. Water Res. 88, 475-480. doi:10.1016/j.watres.2015.10.028

Jiang, W., Mashayekhi, H., Xing, B., 2009. Bacterial toxicity comparison between nano- and microscaled oxide particles. Environ. Pollut. 157, 1619-1625. doi:10.1016/j.envpol.2008.12.025

Johnston, E.L., Roberts, D.A., 2009. Contaminants reduce the richness and evenness of marine communities: A review and meta-analysis. Environ. Pollut. 157, 1745-1752. doi:10.1016/j.envpol.2009.02.017

Karn, B., Kuiken, T., Otto, M., 2009. Nanotechnology and in situ remediation: A review of the benefits and potential risks. Environ. Health Perspect. 117, 1823-1831. doi:10.1289/ehp.0900793

Khan, F.I., Husain, T., Hejazi, R., 2004. An overview and analysis of site remediation technologies. J. Environ. Manage. 71, 95-122. doi:10.1016/j.jenvman.2004.02.003

Kirschling, T.L., Gregory, K.B., Minkley, E.G., Lowry, G. V., Tilton, R.D., 2010. Impact of nanoscale zero valent iron on geochemistry and microbial populations in trichloroethylene contaminated aquifer materials. Environ. Sci. Technol. 44, 3474-3480. doi:10.1021/es903744f

Kovrižnych, J. a, Sotníková, R., Zeljenková, D., Rollerová, E., Szabová, E., Wimmerová, S., 2013. Acute toxicity of 31 different nanoparticles to zebrafish (Danio rerio) tested in adulthood and in early life stages - comparative study. Interdiscip. Toxicol. 6, 67-73. doi:10.2478/intox-2013-0012

Lefevre, E., Bossa, N., Wiesner, M.R., Gunsch, C.K., 2015. A review of the environmental implications of in situ remediation by nanoscale zero valent iron (nZVI): Behavior, transport and impacts on microbial communities. Sci. Total Environ. 565, 889-901. doi:10.1016/j.scitotenv.2016.02.003

Lüderwald, S., Seitz, F., Seisenbaeva, G.A., Kessler, V.G., Schulz, R., Bundschuh, M., 2016. Palladium Nanoparticles: Is There a Risk for Aquatic Ecosystems? Bull. Environ. Contam. Toxicol. doi:10.1007/s00128-016-1803-x 
Ma, X.Y., Wang, X.C., Ngo, H.H., Guo, W., Wu, M.N., Wang, N., 2014. Bioassay based luminescent bacteria: interferences, improvements, and applications. Sci. Total Environ. 468-469, 1-11. doi:10.1016/j.scitotenv.2013.08.028

Macé, C., Desrocher, S., Gheorghiu, F., Kane, A., Pupeza, M., Cernik, M., Kvapil, P., Venkatakrishnan, R., Zhang, W., 2006. Nanotechnology and groundwater remediation: A step forward in technology understanding. Remediat. J. 16, 23-33. doi:10.1002/rem.20079

Marzorati, M., Wittebolle, L., Boon, N., Daffonchio, D., Verstraete, W., 2008. How to get more out of molecular fingerprints: practical tools for microbial ecology. Environ. Microbiol. 10, 1571-81. doi:10.1111/j.1462-2920.2008.01572.x

Mertens, B., Blothe, C., Windey, K., De Windt, W., Verstraete, W., 2007. Biocatalytic dechlorination of lindane by nano-scale particles of $\operatorname{Pd}(0)$ deposited on Shewanella oneidensis. Chemosphere 66, 99-105. doi:10.1016/j.chemosphere.2006.05.018

Moore, M.N., 2006. Do nanoparticles present ecotoxicological risks for the health of the aquatic environment? Environ. Int. 32, 967-976. doi:10.1016/j.envint.2006.06.014

Nowack, B., Bucheli, T.D., 2007. Occurrence, behavior and effects of nanoparticles in the environment. Environ. Pollut. 150, 5-22. doi:10.1016/j.envpol.2007.06.006

Otto, M., Floyd, M., Bajpai, S., 2008. Nanotechnology for site remediation (including fact sheet). Remediat. J. 19, 99-108. doi:10.1002/rem.20194

Perelo, L.W., 2010. Review: In situ and bioremediation of organic pollutants in aquatic sediments. J. Hazard. Mater. 177, 81-9. doi:10.1016/j.jhazmat.2009.12.090

Petrarca, C., Clemente, E., Di Giampaolo, L., Mariani-Costantini, R., Leopold, K., Schindl, R., Lotti, L. V, Mangifesta, R., Sabbioni, E., Niu, Q., Bernardini, G., Di Gioacchino, M., 2014. Palladium Nanoparticles Induce Disturbances in Cell Cycle Entry and Progression of Peripheral Blood Mononuclear Cells: Paramount Role of Ions. J. Immunol. Res. 2014, 1-8. doi:10.1155/2014/295092

Quan, X., Zhang, X., Xu, H., 2015. In-situ formation and immobilization of biogenic nanopalladium into anaerobic granular sludge enhances azo dyes degradation. Water Res. 78, 74-83. doi:10.1016/j.watres.2015.03.024

Read, S., Marzorati, M., Guimarães, B.C.M., Boon, N., 2011. Microbial Resource Management revisited: successful parameters and new concepts. Appl. Microbiol. Biotechnol. 90, 861-871. 
556 Safe, S., 1993. Toxicology, structure-function relationship, and human and environmental health

557

558

559

560

561

562

563

564

565

566

567

568

569

570

571

572

573

574

575

576

577

578

579

580

581

582

583

584 impacts of polychlorinated biphenyls: progress and problems. Environ. Health Perspect. 87, 121920.

Sánchez, A., Recillas, S., Font, X., Casals, E., González, E., Puntes, V., 2011. Ecotoxicity of, and remediation with, engineered inorganic nanoparticles in the environment. TrAC Trends Anal. Chem. 30, 507-516. doi:10.1016/j.trac.2010.11.011

Sass, A.M., Sass, H., Coolen, M.J., Cypionka, H., Overmann, J., 2001. Microbial communities in the chemocline of a hypersaline deep-sea basin (Urania basin, Mediterranean Sea). Appl. Environ. Microbiol. 67, 5392-402. doi:10.1128/AEM.67.12.5392-5402.2001

Schrand, A.M., Rahman, M.F., Hussain, S.M., Schlager, J.J., Smith, D.A., Syed, A.F., 2010. Metalbased nanoparticles and their toxicity assessment. Wiley Interdiscip. Rev. Nanomedicine Nanobiotechnology. doi:10.1002/wnan.103

Scoma, A., Bertin, L., Zanaroli, G., Fraraccio, S., Fava, F., 2011. A physicochemical-biotechnological approach for an integrated valorization of olive mill wastewater. Bioresour. Technol. 102, 102739. doi:10.1016/j.biortech.2011.08.080

Serrano, E., 2010. Nanotechnology and the Environment. Mater. Today 13, 55. doi:10.1016/S13697021(10)70089-4

Shah, V., Belozerova, I., 2009. Influence of metal nanoparticles on the soil microbial community and germination of lettuce seeds. Water. Air. Soil Pollut. 197, 143-148. doi:10.1007/s11270-0089797-6

Sowers, K.R., May, H.D., 2013. In situ treatment of PCBs by anaerobic microbial dechlorination in aquatic sediment: are we there yet? Curr. Opin. Biotechnol. 24, 482-8. doi:10.1016/j.copbio.2012.10.004

Speranza, A., Leopold, K., Maier, M., Taddei, A.R., Scoccianti, V., 2010. Pd-nanoparticles cause increased toxicity to kiwifruit pollen compared to soluble Pd(II). Environ. Pollut. 158, 873-882. doi:10.1016/j.envpol.2009.09.022

Stockholm Convention, 2004. Listing of POPs in the Stockholm Convention (updated May 2013) [WWW Document].

URL http://chm.pops.int/TheConvention/ThePOPs/ListingofPOPs/tabid/2509/Default.aspx 
585

Theron, J., Walker, J. a, Cloete, T.E., 2008. Nanotechnology and water treatment: applications and emerging opportunities. Crit. Rev. Microbiol. 34, 43-69. doi:10.1080/10408410701710442

Tilman, D., Isbell, F., Cowles, J.M., 2014. Biodiversity and Ecosystem Functioning. Annu. Rev. Ecol. Evol. Syst. 45, 471-493. doi:10.1146/annurev-ecolsys-120213-091917

Tilston, E.L., Collins, C.D., Mitchell, G.R., Princivalle, J., Shaw, L.J., 2013. Nanoscale zerovalent iron alters soil bacterial community structure and inhibits chloroaromatic biodegradation potential in Aroclor 1242-contaminated soil. Environ. Pollut. 173, 38-46. doi:10.1016/j.envpol.2012.09.018

Ukisu, Y., Miyadera, T., 2003. Hydrogen-transfer hydrodechlorination of polychlorinated dibenzo-pdioxins and dibenzofurans catalyzed by supported palladium catalysts. Appl. Catal. B Environ. 40, 141-149. doi:10.1016/S0926-3373(02)00148-0

US Environmental Protection Agency, 2014. Technical Fact sheet - Nanomaterials At a Glance [WWW Document]. Off. Solid Waste Emerg. Response, EPA 505-F-14-004. URL http://nepis.epa.gov/Exe/ZyNET.exe/P100MWS9.TXT?ZyActionD=ZyDocument\&Client=EPA\& Index $=2011+$ Thru $+2015 \&$ Docs $=\& Q$ Query $=\&$ Time $=\&$ EndTime $=\&$ SearchMethod $=1 \&$ TocRestrict $=$ $\mathrm{n} \& \mathrm{Toc}=\&$ TocEntry $=\& Q$ Field $=\& Q$ FieldYear $=\& Q$ FieldMonth $=\& Q$ FieldDay $=\&$ IntQFieldOp $=0 \&$ ExtQFieldOp $=0 \& X m l Q u e r y=\&$

US Environmental Protection Agency, 2007. Nanotechnology white paper [WWW Document]. Sr. Policy Counc. EPA 100/B-07/001. URL http://www.epa.gov/osainter/pdfs/nanotech/epananotechnology-whitepaper-0207.pdf

van Beelen, P., 2003. A review on the application of microbial toxicity tests for deriving sediment quality guidelines. Chemosphere 53, 795-808. doi:10.1016/S0045-6535(03)00716-1

Wang, Z., Zhang, L., Zhao, J., Xing, B., 2016. Environmental processes and toxicity of metallic nanoparticles in aquatic systems as affected by natural organic matter. Environ. Sci. Nano 3, 240 255. doi:10.1039/C5EN00230C

Wiegel, J., Wu, Q., 2000. Microbial reductive dehalogenation of polychlorinated biphenyls. FEMS Microbiol. Ecol. doi:10.1016/S0168-6496(00)00014-3

Wiesner, M.R., Lowry, G. V., Alvarez, P., Dionysiou, D., Biswas, P., 2006. Assessing the risks of manufactured nanomaterials. Environ. Sci. Technol. 40, 4336-4345. doi:10.1021/es062726m

Wittebolle, L., Marzorati, M., Clement, L., Balloi, A., Daffonchio, D., Heylen, K., De Vos, P., Verstraete, W., Boon, N., 2009. Initial community evenness favours functionality under selective 
616 Xiu, Z. ming, Jin, Z. hui, Li, T. long, Mahendra, S., Lowry, G. V., Alvarez, P.J.J., 2010. Effects of 617 nano-scale zero-valent iron particles on a mixed culture dechlorinating trichloroethylene. 618 Bioresour. Technol. 101, 1141-1146. doi:10.1016/j.biortech.2009.09.057

619 Xiu, Z.M., Gregory, K.B., Lowry, G. V., Alvarez, P.J.J., 2010. Effect of bare and coated nanoscale 620 zerovalent iron on tceA and vcrA gene expression in Dehalococcoides spp. Environ. Sci. Technol. $62144,7647-7651$. doi:10.1021/es101786y

622 Zanaroli, G., Balloi, A., Negroni, A., Borruso, L., Daffonchio, D., Fava, F., 2012a. A Chloroflexi 623 bacterium dechlorinates polychlorinated biphenyls in marine sediments under in situ-like 624 biogeochemical conditions. J. Hazard. Mater. 209-210, $449-57$. 625 doi:10.1016/j.jhazmat.2012.01.042

626 Zanaroli, G., Balloi, A., Negroni, A., Daffonchio, D., Young, L.Y., Fava, F., 2010. Characterization of 627 the microbial community from the marine sediment of the Venice lagoon capable of reductive 628 dechlorination of coplanar polychlorinated biphenyls (PCBs). J. Hazard. Mater. 178, 417-26. doi:10.1016/j.jhazmat.2010.01.097

630 Zanaroli, G., Negroni, A., Häggblom, M.M., Fava, F., 2015. Microbial dehalogenation of 631 organohalides in marine and estuarine environments. Curr. Opin. Biotechnol. 33, $287-295$. 632 doi:10.1016/j.copbio.2015.03.013

633 Zanaroli, G., Negroni, A., Vignola, M., Nuzzo, A., Shu, H.-Y., Fava, F., 2012b. Enhancement of 634 microbial reductive dechlorination of polychlorinated biphenyls (PCBs) in a marine sediment by 635 nanoscale zerovalent iron (NZVI) particles. J. Chem. Technol. Biotechnol. 87, 1246-1253. 636 doi: $10.1002 /$ jctb.3835

637 Zanaroli, G., Pérez-Jiménez, J.R., Young, L.Y., Marchetti, L., Fava, F., 2006. Microbial reductive 638 dechlorination of weathered and exogenous co-planar polychlorinated biphenyls (PCBs) in an 639 anaerobic sediment of Venice Lagoon. Biodegradation 17, 121-9. doi:10.1007/s10532-005-3752640 7

641 Zhang, W.X., 2003. Nanoscale iron particles for environmental remediation: An overview. J. 642 Nanoparticle Res. 5, 323-332. doi:10.1023/A:1025520116015 


\section{Figure Captions}

644 Figure 1. Bioluminescence inhibition of $V$. fischeri in acute toxicity tests after 5, 15 and 30 minutes

645 exposure to different dilutions of bio-Pd NPs in marine filter-sterilized water. The highest

646 concentration of bio-Pd NPs corresponds to $81.9 \%$ of the $50 \mathrm{mg} / \mathrm{kgdw}$ concentration at which bio-Pd

647 NPs were applied in the microcosms experiment. Inhibition is calculated in percentage against control

648 with no bio-Pd NPs. Values are means of duplicate analysis.

649 Figure 2. Dechlorination of Aroclor 1254 PCBs over time in the biologically active (inoculated) and 650 sterile (non inoculated) sets of spiked microcosms. Values are means of triplicate microcosms, with 651 error bars representing standard deviation.

652 Figure 3. Concentrations of spiked PCB congeners and their dechlorination products constituting more 653 than $1 \% \mathrm{w} / \mathrm{w}$ of total PCBs at the end of incubation in the biologically active (white bars) and sterile 654 (black bars) sets of spiked microcosms. (a) unamended microcosms; (b) hydrogen-amended 655 microcosms; (c) microcosms amended with hydrogen + bioPd 5mg/kgdw; (d) microcosms amended 656 with hydrogen + bio-Pd $50 \mathrm{mg} / \mathrm{kgdw}$. Values are means of triplicate microcosms with error bars 657 representing standard deviation.

658 Figure 4. Sulfate concentration (a) and methane production (b) in the biologically active sets of 659 microcosms spiked and not spiked (No PCB) with Aroclor 1254. Values are means of triplicate 660 microcosms with error bars representing standard deviation.

661 Figure 5. Upper panel: DGGE profiles of the total bacterial community in the biologically active, 662 PCB-spiked set of microcosms at weeks 0, 9 and 18. In each lane, PCR products obtained from the 663 three replicate microcosms were pooled. Lower panel: analysis of the Community organization (Co 664 expressed as Gini percentage times 100, bars) and richness (diamonds) for each DGGE lane.

665 Figure 6. Upper panel: DGGE profiles of the total bacterial community in the biologically active, 666 PCB-free set of microcosms at weeks 0, 9 and 18. In each lane, PCR products obtained from the three 667 replicate microcosms were pooled. Lower panel: analysis of the Community organization (Co 668 expressed as Gini percentage times 100, bars) and richness (diamonds) for each DGGE lane. 


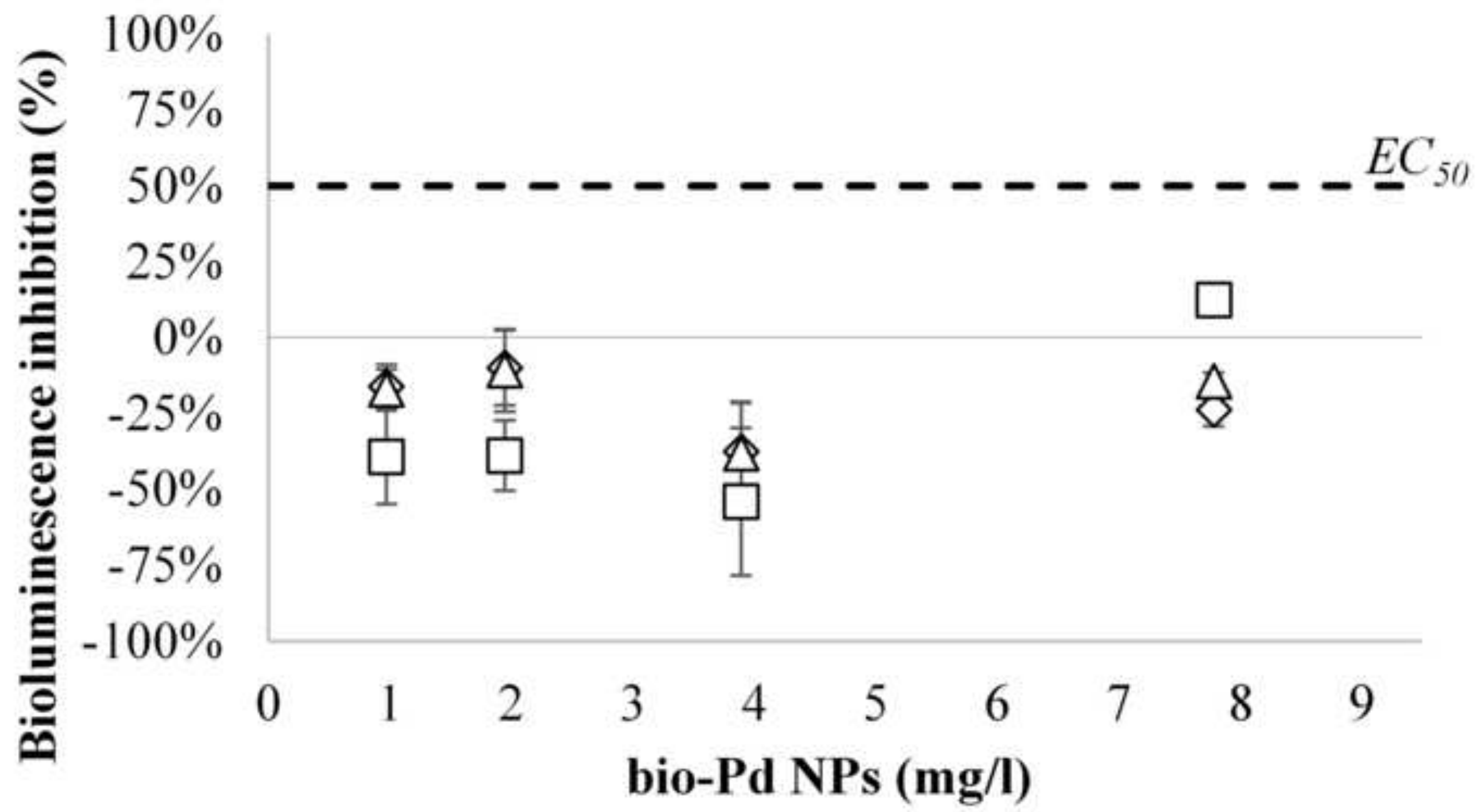

$\square 5 \mathrm{~min} \diamond 15 \mathrm{~min} \Delta 30 \mathrm{~min}$ 


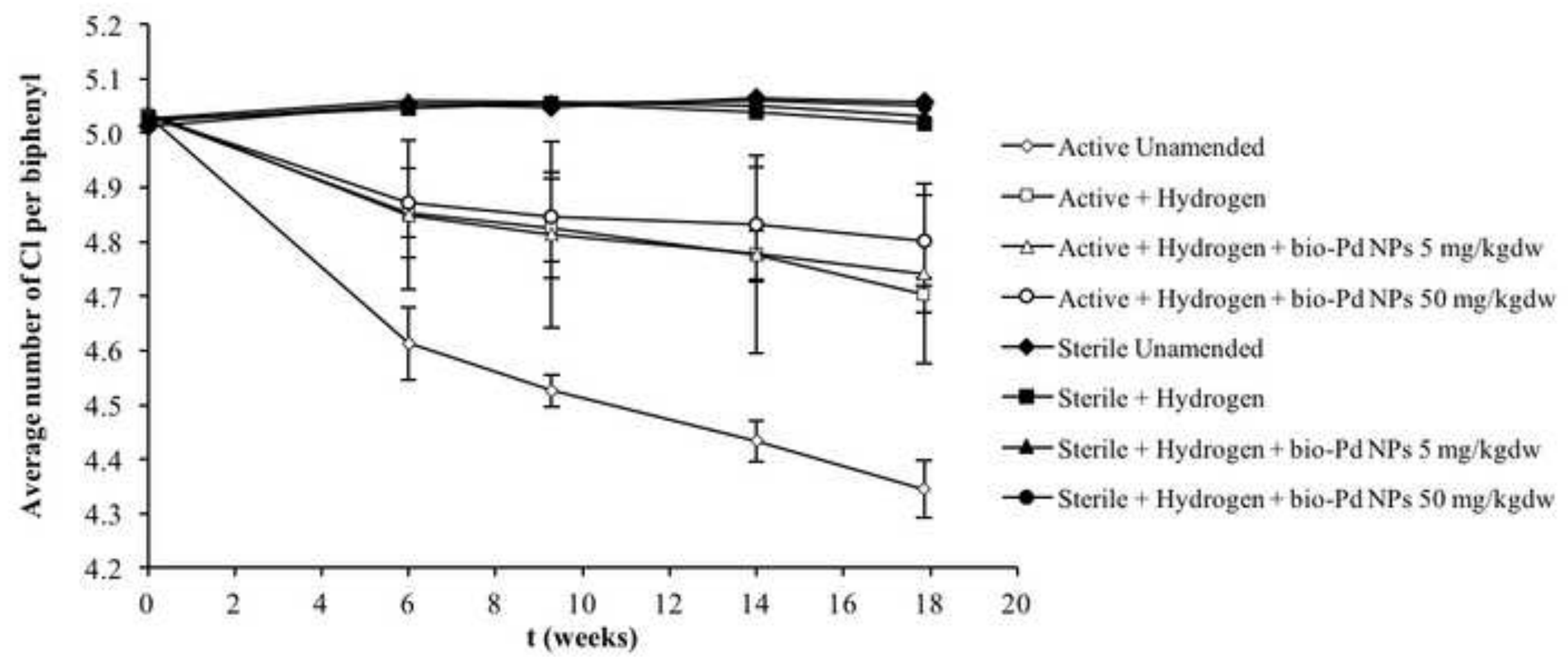


Figure 3

Click here to download high resolution image
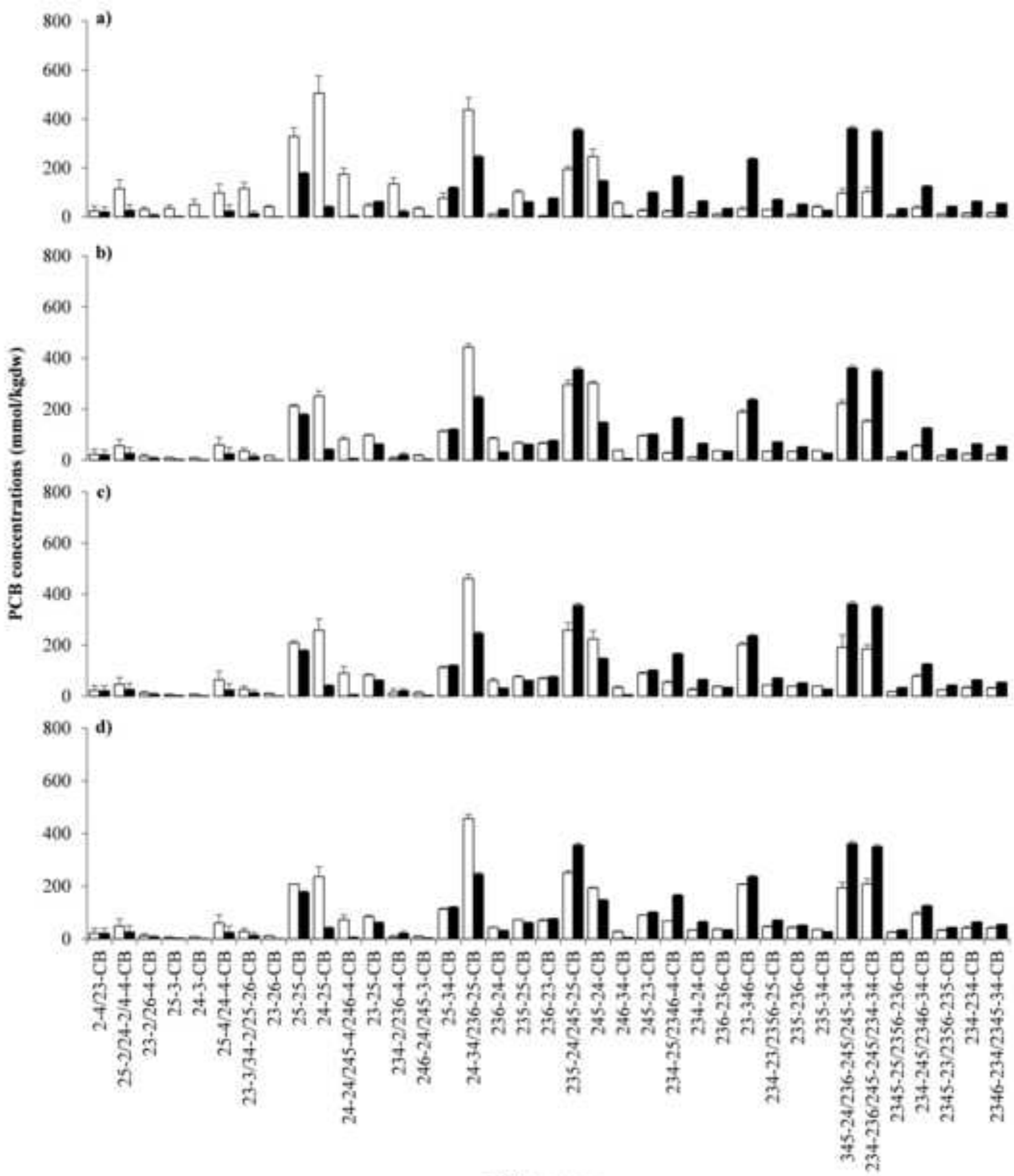

PCB congeners 

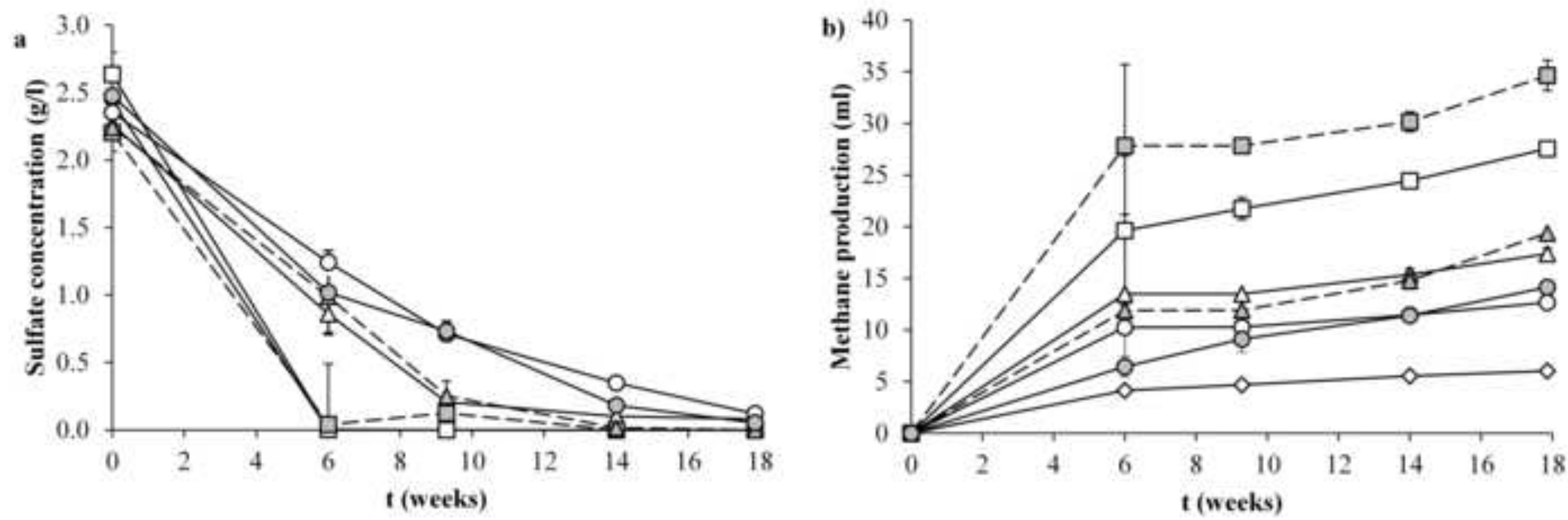

$\infty$ Active Unamended

$-\triangle$-Active + Hydrogen + bio-Pd NPs $5 \mathrm{mg} / \mathrm{kgdw}$

$-\square$ - Active No PCB + Hydrogen

-O-Active No PCB + Hydrogen + bio-Pd NPs $50 \mathrm{mg} / \mathrm{kgdw}$

$-\square-$ Active + Hydrogen

-O-Active + Hydrogen + bio-Pd NPs $50 \mathrm{mg} / \mathrm{kgdw}$

$-\Delta$-Active No PCB + Hydrogen + bio-Pd NPs $5 \mathrm{mg} / \mathrm{kgdw}$ 
Weeks of incubation

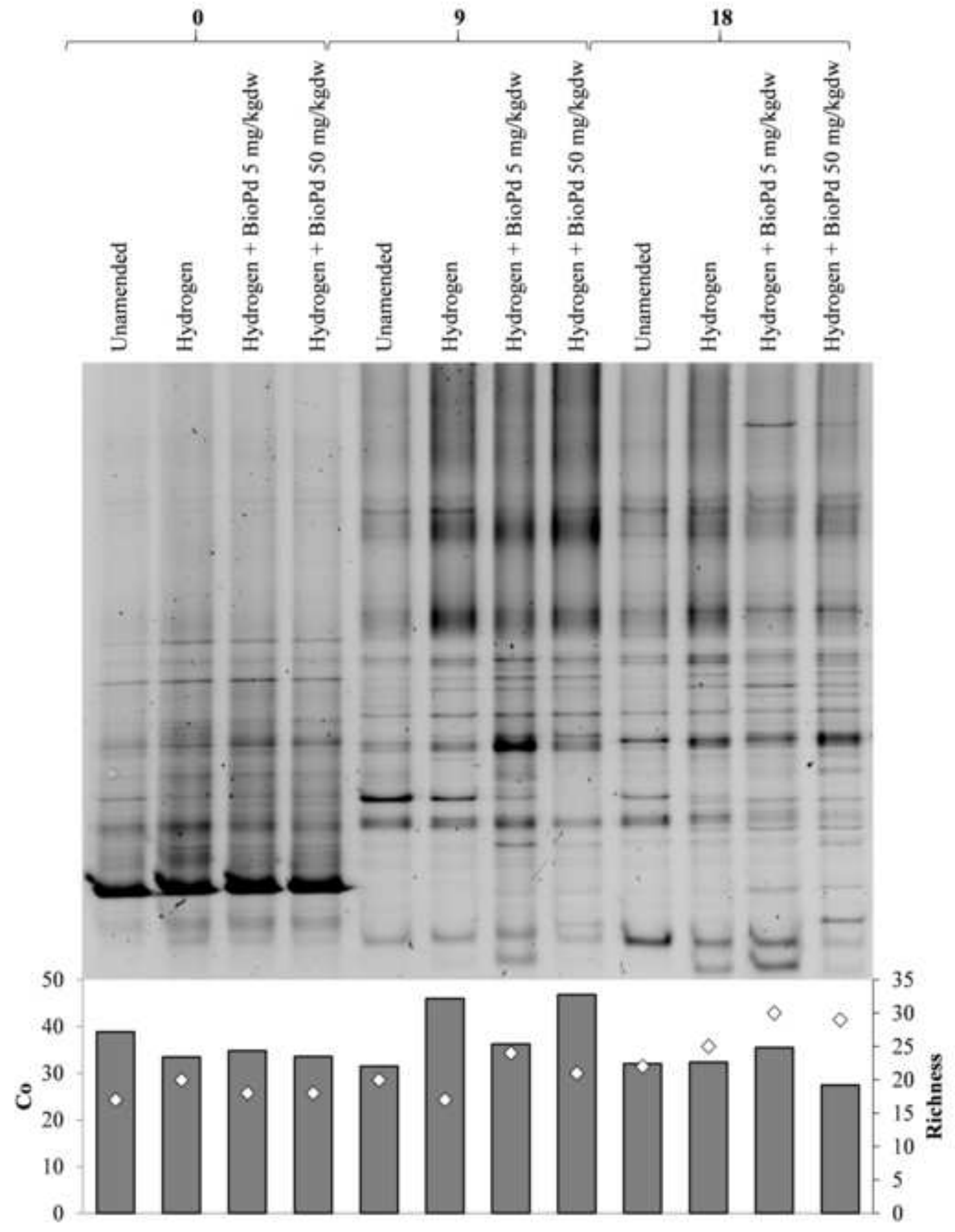




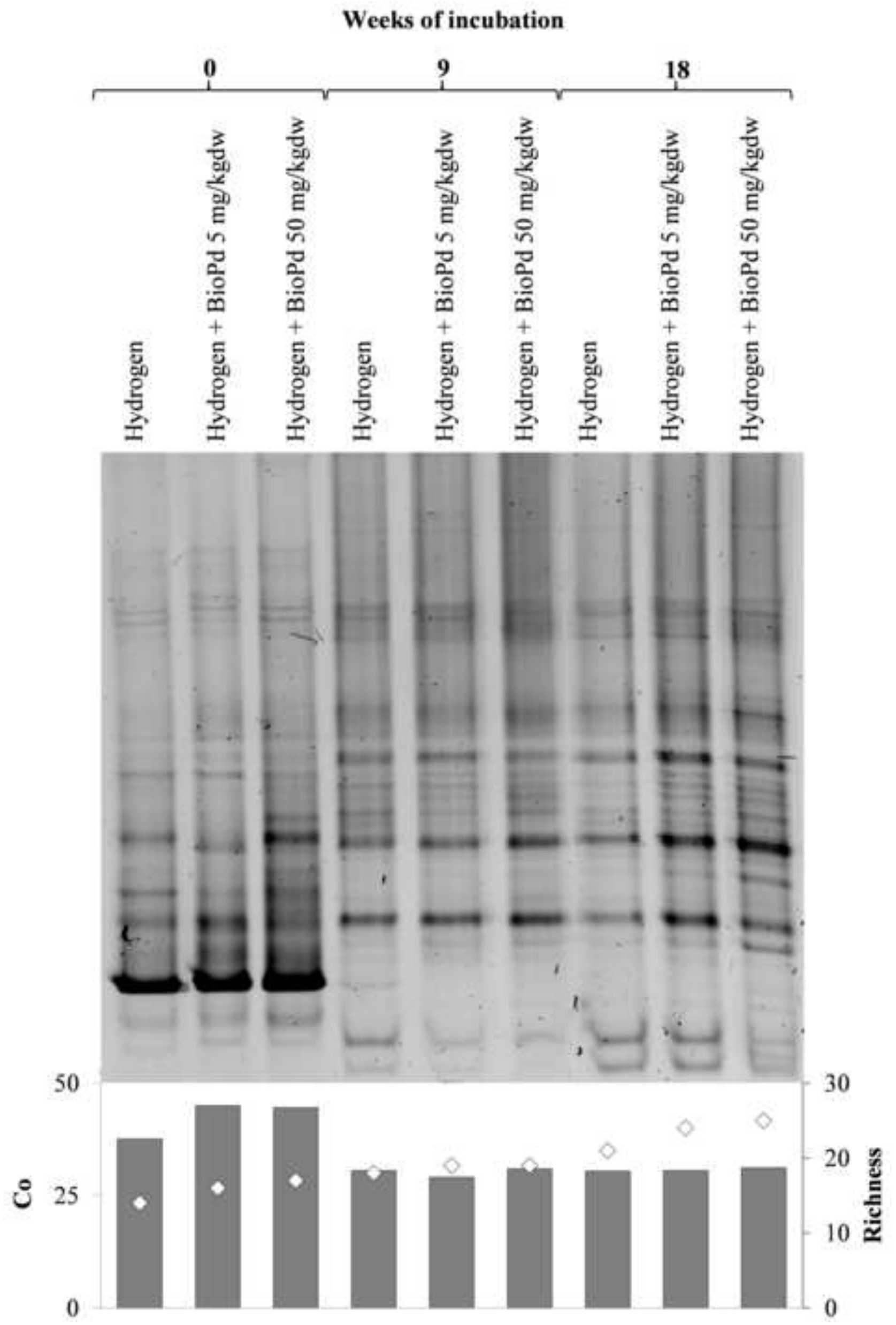

